\title{
Study of changes in biochemical parameters of preeclampsia patients, a prospective five year study
}

\author{
Aditi Saha ${ }^{1}$, Anirban Das Gupta ${ }^{2 *}$ \\ ${ }^{1}$ Department of Biochemistry, ${ }^{2}$ Department of Anatomy, Konaseema Institute of Medical Science, Amalapuram, Andhra \\ Pradesh, India
}

Received: 13 December 2021

Accepted: 06 January 2022

\section{*Correspondence:}

Dr. Anirban Das Gupta,

E-mail: dr.anirbanbsmc@gmail.com

Copyright: ( $)$ the author(s), publisher and licensee Medip Academy. This is an open-access article distributed under the terms of the Creative Commons Attribution Non-Commercial License, which permits unrestricted non-commercial use, distribution, and reproduction in any medium, provided the original work is properly cited.

\begin{abstract}
Background: Preeclampsia is associated with changes in biochemical parameters like hepatic dysfunction, increase in blood glucose, thrombocytopenia, urea, creatinine, uric acid, alteration in lipid profile, hypoalbuminemia, electrolyte and C-reactive protein. Based on variability in literature regarding biochemical parameters present study has been designed to evaluate the changes in biochemical parameters in preeclampsia patients in tertiary care hospital.

Methods: Pregnant women with pre eclampsia attending OPD of obstetrics department were enrolled for this study based on following inclusion and exclusion criteria. Similarly normotensive pregnant women were enrolled as control per same inclusion and exclusion criteria.

Results: Total platelet count was significantly lower in preeclampsia patients then control $(2.02 \pm 0.7 \mathrm{lakh} / \mu \mathrm{l}$ versus $3.29 \pm .58 \mathrm{lakh} / \mu \mathrm{l})$. Blood urea was significantly higher in preeclampsia patients than control $(29.22 \pm 4.56 \mathrm{mg} / \mathrm{dl}$ versus $18.32 \pm 6.23 \mathrm{mg} / \mathrm{dl}),(\mathrm{p}=0.0001)$ serum uric acid was significantly higher in preeclampsia patients than control $(9.22 \pm 1.11$ $\mathrm{mg} / \mathrm{dl}$ versus $5.89 \pm .89 \mathrm{mg} / \mathrm{dl})$. HOMA IR was significantly higher in preeclampsia patients then control $(4.52 \pm 1.68$ versus $2.23 \pm 1.98$ ).

Conclusions: From present study we can conclude preeclampsia patients were frequent in nulliparous. Preeclampsia is associated with thrombocytopenia. Except increase in AST other hepatic parameters were in normal range and comparable to control. FPG, FPI and HOMA IR were elevated in our finding and it indicates a state of insulin resistance. Preeclampsia patients were also having dyslipidemia. Serum uric acid creatinine and blood urea was significantly higher in preeclampsia patients.
\end{abstract}

Keywords: Biochemical parameters, HOMA IR, Preeclampsia

\section{INTRODUCTION}

Preeclampsia is the major cause of perinatal death, IUGR, pre term death, maternal mortality and morbidity in developing country. ${ }^{1}$ The incidence of preeclampsia is as high as $28 \%$ and ranges from $7.4-11.3 \%$ in India. ${ }^{2}$ Preeclampsia is multisystem disorder of pregnancy, which is characterized by new onset hypertension (systolic and diastolic blood pressure of $\geq 140$ and $90 \mathrm{mmHg}$, respectively, on two occasions, at least 6 hours apart) and proteinuria (protein excretion of $\geq 300 \mathrm{mg}$ in a 24 -hour urine collection, or a dipstick of $\geq 2+$ ), that develop after 20 weeks of gestation in previously normotensive women. ${ }^{3-5}$ Classically; the American College of Obstetrics and Gynecology (ACOG) defines preeclampsia as the presence of hypertension and proteinuria occurring after 20 weeks of gestation in a previously normotensive patient. ${ }^{6}$ Preeclampsia is associated with changes in biochemical parameters like hepatic dysfunction, increase in blood glucose, thrombocytopenia, urea, creatinine, uric acid, alteration in lipid profile, hypoalbuminemia, electrolyte and C-reactive protein. After going through literature we have observed that there is variability in the conclusion of various author regarding changes in biochemical parameters. 
Karar et al has reported that the elevated values of serum creatinine, urea, urine protein, sodium, potassium and plasma glucose preclude them to be useful for consideration as consistent predictive indicator(s) for preeclampsia or pregnancy related hypertension. ${ }^{7}$ Ahmed et al has reported that pre-eclampsia is associated with generalized activation of circulating leukocytes and increased concentrations of C-reactive protein (CRP). ${ }^{8}$ Ekun et al has concluded that preeclampsia has deleterious effects on renal and liver function as shown by alteration of these parameters. ${ }^{9}$ Quan et al has conclude that multivariate analysis results in this study revealed that the following elements are high risk factors for preeclampsia: hypertension history, advanced age, high blood lipids, high BMI and pregnant women with diabetes history. ${ }^{10}$

Based on above literature present study has been designed to evaluate the changes in biochemical parameters in preeclampsia patients in tertiary care hospital.

\section{METHODS}

\section{Place of study}

Present study has been conducted in the department of biochemistry and obstetrics and gynaecology Konaseema institute of medical science Amalapuram Andhra Pradesh India. It has been conducted from December 2016 to March 2021.

\section{Type of study}

This was a prospective comparative observational study.

\section{Ethics}

This study was approved by institutional ethics committee. A written informed consent was taken from all patients before enrolling them for study.

\section{Selection of patients}

Pregnant women with pre eclampsia attending OPD of obstetrics department were enrolled for this study based on following inclusion and exclusion criteria. Similarly normotensive pregnant women were enrolled as control per same inclusion and exclusion criteria.

\section{Inclusion criteria}

Pregnant women between 20 to 45 years of age. Diagnosed case of preeclampsia with singleton pregnancy. Normotensive singleton pregnancy as control.

\section{Exclusion criteria}

Gestational diabetes mellitus, renal disease, cardiovascular disorder, immunological disorder, PCOS and other preexisting metabolic disorder. Multiple pregnancies.

\section{Sample size}

Based on above mentioned criteria and statistical analysis 120 patients were enrolled in study during study period and divided in to two groups, group 1-normotensive subjects, group 2- pre-eclampsia subjects.

During the study period of two years and three month 224 subjects were enrolled for present and divided in to two groups. Group 1- normotensive singleton pregnancy, group 2- singleton pregnancy diagnosed to be preeclampsia.

A detailed history of present pregnancy and previous pregnancy in multiparous was taken. Height and weight of patient was noted from antenatal record and weight gain was noted from previous record. BMI was calculated. Palpatory method and auscultatory method was used for measurement of blood pressure in supine and sitting position. Systolic BP was taken by Korotkoff sound (phase I) and diastolic BP was taken by Korotkoff sound (phase V).

"Hypertension was defined as a diastolic blood pressure of at least $90 \mathrm{mmHg}$ or a systolic pressure of at least 140 $\mathrm{mmHg}$ or an increase in the former of at least $15 \mathrm{mmHg}$ or in the latter of $30 \mathrm{mmHg}$ on 2 occasions that were more than 4 hours apart or a single diastolic blood pressure reading of $110 \mathrm{mmHg}$ or greater" as per World Health Organization. ${ }^{11}$

After prior information and explaining the technique $5 \mathrm{ml}$ of blood sample will be drawn from all the subjects following overnight fast of 8 to 10 hours. Various parameters like, complete blood count haemoglobin level, total leukocyte count, platelet count, blood urea nitrogen, creatinine, aspartate transaminase (AST), alanine transaminase (ALT), alkaline phosphatase (ALP), electrolytes (sodium, potassium), uric acid, fasting plasma glucose, post prandial plasma glucose, HDL-C, LDL-c, TG total cholesterol, fasting plasma insulin, and HOMAIR were measured. Hexokinase method was used for estimation of plasma glucose. For total cholesterol, we used Liebermann Burchard reaction colorimetric method; triglyceride was estimated by method of Neri and Fringe. HDL concentration was estimated by precipitation method. LDL concentration was calculated by WHO formula, LDL- cholesterol $=$ total cholesterol $-\mathrm{TG} / 5-$ HDL (mg/dl). ${ }^{12}$ Plasma insulin was determined by using enzyme linked immunosorbent assay. HOMA-IR was calculated by using this formula $($ FPI $\times$ FPG $) / 22.5 .{ }^{13}$

\section{Sample size calculation}

Based on mean and standard deviation of previous studies, at $95 \%$ confidence intervals, $80 \%$ power and ratio of sample as 1, the sample size for finding the mean difference among two groups were computed to be 2.6 and standard deviation 0.5. A total sample size of 60 was taken, assuming equal group sizes. ${ }^{14}$ 


\section{Statistical analysis}

Data was recorded in excel sheet and statistical analysis was done with software SPSS-14 version. Qualitative data was calculated as percentage and proportions and was analysed by Chi-square test. Quantitative data was expressed as mean $\pm \mathrm{SD}$ and these data were analysed by unpaired student $\mathrm{t}$ test.

\section{RESULTS}

In present prospective observational study sixty patients diagnosed to be preeclampsia and sixty healthy normotensive patients were enrolled for this study as per selection criteria.

Table 1: Demography of study population.

\begin{tabular}{|c|c|c|c|c|}
\hline \multicolumn{2}{|c|}{ Variables } & Preeclampsia patients & Control & P value \\
\hline \multicolumn{2}{|c|}{ Age } & $32.42 \pm 6.45$ & $26.44 \pm 8.14$ & 0.0001 \\
\hline \multicolumn{2}{|c|}{ BMI $\left(\mathrm{kg} / \mathrm{m}^{2}\right)$} & $26.11 \pm 2.46$ & $23.19 \pm 1.42$ & 0.02 \\
\hline \multicolumn{2}{|c|}{ SBP (mm of Hg) } & $146.32 \pm 8.21$ & $110.86 \pm 12.54$ & 0.0001 \\
\hline \multicolumn{2}{|c|}{ DBP $(\mathbf{m m}$ of $\mathbf{H g})$} & $94.46 \pm 6.84$ & $79.44 \pm 6.47$ & 0.0001 \\
\hline \multirow{2}{*}{ Parity } & Nulliparous & 38 & 26 & \multirow{2}{*}{0.027} \\
\hline & Multiparous & 22 & 34 & \\
\hline
\end{tabular}

Table 2: Comparison of biochemical parameters in preeclampsia patients and control.

\begin{tabular}{|c|c|c|c|}
\hline Variables & Preeclampsia patients & Control & P value \\
\hline Hemoglobin (gm/dl) & $11.54 \pm 1.5$ & $10.83 \pm 1.64$ & 0.07 \\
\hline Total platelet count $(\mathrm{lakh} / \mu \mathrm{l})$ & $2.02 \pm 0.7$ & $3.29 \pm 0.58$ & 0.0001 \\
\hline Total leukocyte count ( thousand cells per $\mathbf{m m}^{\mathbf{3}}$ ) & $6.86 \pm 0.98$ & $6.47 \pm 0.66$ & 0.55 \\
\hline Serum creatinine $(\mathrm{mg} / \mathrm{dl})$ & $1.65 \pm 0.22$ & $1.04 \pm 0.16$ & 0.00001 \\
\hline Blood urea (mg/dl) & $29.22 \pm 4.56$ & $18.32 \pm 6.23$ & 0.0001 \\
\hline Serum uric acid & $9.22 \pm 1.11$ & $5.89 \pm 0.89$ & 0.0001 \\
\hline $\operatorname{AST}(\mathbf{U} / \mathbf{l})$ & $36.46 \pm 4.78$ & $31.78 \pm 7.54$ & 0.01 \\
\hline $\mathbf{A L T}(\mathbf{U} / \mathbf{l})$ & $44.65 \pm 6.32$ & $42.22 \pm 5.44$ & 0.45 \\
\hline Alkaline phosphatase (IU/I) & $132.22 \pm 12.36$ & $136.65 \pm 14.21$ & 0.07 \\
\hline Total bilirubin (mg/dl) & $1.05 \pm 0.16$ & $1.07 \pm 0.15$ & 0.39 \\
\hline Sodium (mEq/l) & $137.23 \pm 5.12$ & $139.21 \pm 4.96$ & 0.21 \\
\hline Potassium (mEq/l) & $3.14 \pm 0.42$ & $4.05 \pm 0.22$ & 0.0001 \\
\hline FPG (mg/dl) & $84.42 \pm 5.41$ & $79.32 \pm 4.42$ & 0.03 \\
\hline FPI (mIU/dl) & $16.44 \pm 5.48$ & $4.12 \pm 2.21$ & 0.0001 \\
\hline HOMA.IR & $4.52 \pm 1.68$ & $2.23 \pm 1.98$ & 0.0001 \\
\hline HDL (mg/dl) & $36.82 \pm 2.96$ & $41.41 \pm 4.21$ & 0.0001 \\
\hline LDL (mg/dl) & $154.41 \pm 32.12$ & $104.62 \pm 10.24$ & 0.0001 \\
\hline TG (mg/dl) & $186.48 \pm 19.66$ & $126.11 \pm 21.26$ & 0.0001 \\
\hline Total cholesterol (mg/dl) & $184.36 \pm 28.86$ & $147.24 \pm 28.46$ & 0.0001 \\
\hline
\end{tabular}

Regarding demographic profile of patient, the mean of the patients with preeclampsia was $32.42 \pm 6.45$ years whish was significantly higher than control that is $26.44 \pm 8.14$ years $(p=0.0001)$.the body mass index was significantly higher in preeclampsia patients than control $(26.11 \pm 2.46$ $\mathrm{kg} / \mathrm{m}^{2}$ versus $\left.23.19 \pm 1.42 \mathrm{~kg} / \mathrm{m}^{2}\right)$. Mean of systolic (146.32 $\pm 8.21 \mathrm{~mm}$ of $\mathrm{Hg}$ versus $110.86 \pm 12.54 \mathrm{~mm}$ of $\mathrm{Hg}$ ) and diastolic $(94.46 \pm 6.84 \mathrm{~mm}$ of $\mathrm{Hg}$ versus $79.44 \pm 6.47$ $\mathrm{mm}$ of $\mathrm{Hg}$ ) blood pressure was significantly higher inpatients then control. There was significant difference between two groups regarding parity (Table 1).
Regarding comparison of biochemical parameters in preeclampsia patients and control, mean of haemoglobin concentration between two group were comparable to each other $(11.54 \pm 1.5 \mathrm{gm} / \mathrm{dl}$ versus $10.83 \pm 1.64 \mathrm{gm} / \mathrm{dl})$. Total platelet count was significantly lower in preeclampsia patients then control $(2.02 \pm 0.7 \mathrm{lakh} / \mu \mathrm{l}$ versus $3.29 \pm 0.58$ lakh/ $\mu 1)$. Total leukocytes were comparable to each other in both groups. Serum creatinine was significantly higher in preeclampsia patients than control $(1.65 \pm .22 \mathrm{mg} / \mathrm{dl}$ versus $1.04 \pm 0.16 \mathrm{mg} / \mathrm{dl}) \quad(\mathrm{p}=0.0001)$, blood urea was significantly higher in preeclampsia patients than control $(29.22 \pm 4.56 \mathrm{mg} / \mathrm{dl}$ versus $18.32 \pm 6.23 \mathrm{mg} / \mathrm{dl}),(\mathrm{p}=0.0001)$ serum uric acid was significantly higher in preeclampsia 
patients than control $(9.22 \pm 1.11 \mathrm{mg} / \mathrm{dl}$ versus $5.89 \pm .89$ $\mathrm{mg} / \mathrm{dl})(\mathrm{p}=0.0001)$. Serum AST was significantly higher in preeclampsia patients then control but ALT, alkaline phosphotase and total bilirubin was comparable to each other. The difference between serum sodium concentrations was not significant but serum potassium concentration was significantly lower in preeclampsia patients then control $(3.14 \pm 0.42 \mathrm{mEq} / \mathrm{l}$ versus $4.05 \pm 0.22$ $\mathrm{mEq} / \mathrm{l})$.

Fasting plasma glucose was higher in preeclampsia patients the control $(84.42 \pm 5.41 \mathrm{mg} / \mathrm{dl}$ versus $79.32 \pm 4.42$ $\mathrm{mg} / \mathrm{dl})$, fasting plasma insulin was higher in preeclampsia patients the control $(16.44 \pm 5.48 \mathrm{mIU} / \mathrm{dl}$ versus $4.12 \pm 2.21$ $\mathrm{mIU} / \mathrm{dl})$. HOMA IR was significantly higher in preeclampsia patients then control $(4.52 \pm 1.68$ versus $2.23 \pm 1.98)$.

Regarding lipid profile of patients' serum HDL concentration was significantly lower in preeclampsia then control $(36.82 \pm 2.96 \mathrm{mg} / \mathrm{dl}$ versus $41.41 \pm 4.21 \mathrm{mg} / \mathrm{dl})$, serum LDL concentration was significantly higher in preeclampsia then control $(154.41 \pm 32.12 \mathrm{mg} / \mathrm{dl}$ versus $104.62 \pm 10.24 \mathrm{mg} / \mathrm{dl}$ ), serum TG concentration was significantly higher in preeclampsia then control $(186.48 \pm 19.66 \mathrm{mg} / \mathrm{dl}$ versus $126.11 \pm 21.26 \mathrm{mg} / \mathrm{dl})$ and serum total cholesterol concentration was significantly higher in preeclampsia then control $(184.36 \pm 28.86 \mathrm{mg} / \mathrm{dl}$ versus $147.24 \pm 28.46 \mathrm{mg} / \mathrm{dl})$.

\section{DISCUSSION}

In present study we have enrolled sixty patients with eclampsia to study the changes in biochemical parameters in them and compare with healthy control.

We have observed that mean age of patients with preeclampsia was higher than control. Lamminpää et al has concluded that preeclampsia is more common in women with advanced maternal age. Advanced maternal age is an independent risk factor for adverse outcomes in first-time mothers with preeclampsia this finding support our study. ${ }^{15}$ Ananth et al has reported that age and birth cohort effects appear to be primarily responsible for the increase in preeclampsia cases. This finding is in agreement with our study. ${ }^{16}$ Motedayen et al has reported that there is a significant relationship between BMI and the risk of preeclampsia, so it can be said that BMI may be one of the ways to diagnose preeclampsia. This finding is in agreement with our study. ${ }^{17}$ Lopez-Jaramillo et al has reported that women that developed preeclampsia have increased pre-pregnancy BMI this finding support our study. ${ }^{18}$

Preeclampsia was common in nulliparous then multi, this finding is supported by the work of Maeda et al and Long et al. ${ }^{19,20}$ Both SBP and DBP were significantly higher in preeclampsia patients.
Thrombocytopenia was common in preeclampsia patients but haemoglobin concentration and leukocyte count was in normal range and comparable with control. Habas et al has reported that gestational thrombocytopenia (GT) is recognized as a major cause of thrombocytopenia particularly in hypertensive pregnant women during the third trimester. This finding supports our study. ${ }^{21}$ Heilmann et al has reported that non-significant changes were observed in values of plasma viscosity, white cells, platelets, haptoglobin, MCHC, reticulocytes, triglycerides and cholesterol. This finding partially support our study. ${ }^{22}$ Except increase in AST other hepatic parameters were in normal range and comparable to control. Preeclampsia patients were associated with hypokelemia. Munazza et al has reported that raised levels of serum bilirubin and liver enzymes ALT, AST and ALK were found in preeclampsia cases this finding does not support our sturdy. ${ }^{23}$ FPG, FPI and HOMA IR were elevated in our finding and it indicates a state of insulin resistance. Preeclampsia patients were also having dyslipidemia. Berkowitz et al has reported that evidence is beginning to accumulate that preeclampsia is at least partially mediated by insulin resistance as well, and that individuals with preeclampsia may have clinically silent but persistent alterations in insulin resistance. This finding supports our study. ${ }^{24}$ Serum uric acid creatinine and blood urea was significantly higher in preeclampsia patients. This finding is supported by the work of Bainbridge et al and Jeyabalan et al. ${ }^{25,26}$

\section{CONCLUSION}

From present study we can conclude preeclampsia patients were frequent in nulliparous. Preeclampsia is associated with thrombocytopenia. Except increase in AST other hepatic parameters were in normal range and comparable to control. FPG, FPI and HOMA IR were elevated in our finding and it indicates a state of insulin resistance. Preeclampsia patients were also having dyslipidemia. Serum uric acid creatinine and blood urea was significantly higher in preeclampsia patients.

Funding: No funding sources Conflict of interest: None declared

Ethical approval: The study was approved by the Institutional Ethics Committee

\section{REFERENCES}

1. Uzan J, Carbonnel M, Piconne O, Asmar R, Ayoubi JM. Pre-eclampsia: pathophysiology, diagnosis, and management. Vasc Health Risk Manag. 2011;7:46774.

2. Malik A, Jee B, Gupta SK. Preeclampsia: Disease biology and burden, its management strategies with reference to India. Pregnancy Hypertens. 2019;15:2331.

3. Redman CW, Sargent IL. Latest advances in understanding preeclampsia. Science. 2005;308:1592-4. 
4. Sibai B, Dekker G, Kupferminc M. Pre-eclampsia. Lancet. 2005;365:785-99.

5. Monte S. Biochemical markers for prediction of preeclampsia: review of the literature. J Prenat Med. 2011;5(3):69-77.

6. Rana S, Lemoine E, Granger JP, Karumanchi SA. Preeclampsia: pathophysiology, challenges, and perspectives. Circul Res. 2019;124(7):1094-112.

7. Karar T, Fattah MA, Alenazy KR, Alharbi MJ, Alqahtani FM, Al Tamimi W, et al. Assessment of biochemical changes in pregnancy induced hypertension (PIH) among Saudi population at KAMC-Riyadh. J Adv Med Med Res. 2016:1-6.

8. Maged AM, Aid G, Bassiouny N, Eldin DS, Dahab S, Ghamry NK. Association of biochemical markers with the severity of pre-eclampsia. Int $\mathbf{J}$ Gynecol Obstet. 2017;136(2):138-44.

9. Ekun OA, Olawumi OM, Makwe CC, Ogidi NO. Biochemical assessment of renal and liver function among Preeclamptics in Lagos Metropolis. Int J Reprod Med. 2018;2018.

10. Quan LM, Xu QL, Zhang GQ, Wu LL, Xu H. An analysis of the risk factors of preeclampsia and prediction based on combined biochemical indexes. Kaohsiung J Med Sci. 2018;34(2):109-12.

11. Conde-Agudelo A, Villar J, Lindheimer M. World Health Organization systematic review of screening tests for preeclampsia. Obstet Gynecol. 2004;104(6):1367-91.

12. Friedewald WT, Levy RI, Fredrickson DS. Estimation of the concentration of low-density lipoprotein cholesterol in plasma, without use of the preparative ultracentrifuge Clinical Chemistry 1972;18(6):499502

13. Matthews DR, Hosker JP, Rudenski AS, Naylor BA, Treacher DF, Turner RC. Homeostasis model assessment: insulin resistance and $\beta$-cell function from fasting plasma glucose and insulin concentrations in man. Diabetologia. 1985;28(7):4129.

14. Dhand NK, Khatkar MS. Statulator: An online statistical calculator. Sample Size Calculator for Comparing Two Independent Means. Available from: http://statulator.com/SampleSize/ss2M.html. Accessed on 28 April 2021.

15. Lamminpää R, Vehviläinen-Julkunen K, Gissler M, Heinonen S. Preeclampsia complicated by advanced maternal age: a registry-based study on primiparous women in Finland 1997-2008. BMC Pregnancy Childbirth. 2012;12(1):1-5.

16. Ananth CV, Keyes KM, Wapner RJ. Pre-eclampsia rates in the United States, 1980-2010: age-periodcohort analysis. BMJ. 2013;347:f6564.

17. Motedayen M, Rafiei M, Rezaei Tavirani M, Sayehmiri K, Dousti M. The relationship between body mass index and preeclampsia: a systematic review and meta-analysis. Int $\mathbf{J}$ Reprod Biomed. 2019;17(7):463-472.

18. Lopez-Jaramillo P, Barajas J, Rueda-Quijano SM, Lopez-Lopez C, Felix C. Obesity and preeclampsia: common pathophysiological mechanisms. Front Physiol. 2018;9:1838.

19. Maeda Y, Kaneko K, Ogawa K, Sago H, Murashima A. The effect of parity, history of preeclampsia, and pregnancy care on the incidence of subsequent preeclampsia in multiparous women with SLE. Mod Rheumatol. 2021;31(4):843-8.

20. Long PA, Abell DA, Beischer NA. Parity and preeclampsia. Aust N Z J Obstet Gynaecol. 1979;19(4):203-6.

21. Habas E, Rayani A, Ganterie R. Thrombocytopenia in hypertensive disease of pregnancy. J Obstet Gynaecol India. 2013;63(2):96-100.

22. Heilmann L, Rath W, Pollow K. Hemorheological changes in women with severe preeclampsia. Clin Hemorheol Microcirc. 2004;31(1):49-58.

23. Munazza B, Raza N, Naureen A, Khan SA, Fatima F, Ayub M, Sulaman M. Liver function tests in preeclampsia. J Ayub Med Coll Abbottabad. 2011;23(4):3-5.

24. Berkowitz KM. Insulin resistance and preeclampsia. Clin Perinatol. 1998;25(4):873-85.

25. Bainbridge SA, Roberts JM. Uric acid as a pathogenic factor in preeclampsia. Placenta. 2008;29(Suppl A):S67-72.

26. Jeyabalan A, Conrad KP. Renal function during normal pregnancy and preeclampsia. Front Biosci. 2007;12:2425-37.

Cite this article as: Saha A, Gupta AD. Study of changes in biochemical parameters of preeclampsia patients, a prospective five year study. Int J Reprod Contracept Obstet Gynecol 2022;11:517-21. 